\title{
TODA CRIANÇA TEM FAMÍLIA: CRIANÇA EM SITUAÇÃO DE RUA TAMBÉM
}

\author{
Simone dos Santos Paludo \\ Fundação Universidade Federal do Rio Grande, Rio Grande, Brasil \\ Silvia Helena Koller \\ Universidade Federal do Rio Grande do Sul, Porto Alegre, Brasil
}

\begin{abstract}
RESUMO: O presente estudo buscou descrever as características das famílias dos jovens que vivem em situação de rua a partir das percepções desses. Entrevistas semi-estruturadas qualitativas foram aplicadas individualmente com 17 jovens, com idades entre 11 e 16 anos $(M=14,05 ; D P=1,24)$, de ambos os sexos. As entrevistas permitem a compreensão da dinâmica dos fatores de risco que facilitam a ida dos jovens para a vida na rua. A existência de crianças na rua não implica a inexistência da família. Todos os participantes possuíam vínculos com suas famílias, mesmo que frágeis. Apenas cinco participantes voltavam para suas casas todos os dias. Uma variedade de configurações familiares foi descrita pelos jovens. Famílias reconstituídas foram apontadas por $41 \%$ dos participantes e famílias monoparentais, chefiadas por mulheres, por $35 \%$. Identificou-se que a mulher cuidadora tem grande importância dentro da estrutura familiar desta população. Contrastando essa realidade, $58 \%$ dos entrevistados afirmam não conhecer o pai biológico. O número de irmãos que possuem nas suas casas varia entre um e $12(M=5,69 ; D P=3,07)$. A maioria dos pais não possui atividade laboral, ou trabalha em atividades informais. Para ajudar no sustento da família, muitos jovens iniciam o trabalho nas ruas. A violência, a pobreza, a adversidade, os problemas sociais, afetivos e econômicos parecem ter um importante papel na dinâmica e na configuração das famílias dos jovens em situação de rua. É necessário oferecer oportunidades para promover a resiliência dessas famílias.
\end{abstract}

PALAVRAS-CHAVE: Família; jovens em situação de rua; vulnerabilidade.

\section{EVERY CHILD HAS FAMILY: A CHILD IN STREET SITUATION TOO}

ABSTRACT: The study aims to describe the family characteristics of street situation youths from the perception of these youngsters. Individual and qualitative semi-structured interviews with seventeen youths, aged between 11 and 16 years $(M=14,05 ; D P=1,24)$, of both sexes, were conducted. It was an opportunity for understanding the dynamic interplay of risk factors that move youngsters to street life. First, the fact of being on the street does not imply the absence of a family. Children and adolescents enrolled in the study had ties with their families, even when they perceive it as a very fragile one. Only five participants would go back home every day. The participants described a variety of family configurations. Remarriage was pointed out by $41 \%$ and $35 \%$ mentioned a monoparental family configuration, led by a woman. Women who take care of the household are of great importance in this population's family structure. In contrast, $58 \%$ did not know who their fathers are. The number of siblings varied between one and $12(M=5,69 ; D P=3,07)$. The majority of parents were unemployed or involved in informal labor. In order to supplement the family income many children start to work on the streets. Violence, poverty, adversity, associated with social, affective, and economical problems seems to play an important and dynamic role in shaping families characteristics of street youths. It is necessary to offer opportunities to promote resilience for these families. Women had an essential role in family care, and may be a powerful link for development.

KEYWORDS: Families; street situation; vulnerability.

Investigar a relação que a criança e o adolescente em situação de rua mantêm com suas famílias, a princípio, parece um desafio. Embora nas últimas décadas seja notável a mudança na configuração e funcionamento das famílias, é curioso observar que, permanecem tabus e mitos ao que se refere a outros arranjos familiares que fogem ao modelo original e tradicional. A sociedade ainda persiste na transmissão do modelo de família nuclear, ou seja, qualquer composição diferente dessa é classificada como desestruturada. Geralmente, o adjetivo "desestruturado" aparece justificando a falta de condições financeiras para manter as necessidades básicas e criticando a estrutura e a configuração da família principalmente se essa é monoparental. Mas o significado de família parece transcender a estes preceitos e preconceitos. 
A literatura científica oferece diversas definições sobre o termo família. Em 1982, Minuchin ressaltou que a família é um sistema aberto e em constante transformação devido à troca de informações com os sistemas extrafamiliares. Historicamente, a configuração das famílias vem se modificando através do tempo e exigindo uma constante adaptação. Segundo Carter e McGoldrick (1985/1995), tais mudanças são decorrentes, em grande parte, de transformações sócio-econômicas, da reformulação do papel e das tarefas exercidas pela mulher e da pluralidade atual nos arranjos familiares. Essas transformações motivaram a existência de novos arranjos e configurações familiares.

Recentemente, a família tem sido definida como instituição complexa a fim de contemplar a diversidade de relações que convivem na sociedade. As definições psicológicas ampliaram o conceito tradicional de família referindo o grupo familiar como um conjunto de relações, sejam essas consangüíneas ou não (De Antoni \& Koller, 2000). Essa proposta reafirmou que não existe um modelo único e homogêneo de arranjo familiar, mas diferentes configurações que coexistem na sociedade contemporânea e que devem ser isentas de estereótipos. No entanto, o status sócio-econômico parece influenciar na qualificação das famílias, especialmente nas pobres e miseráveis.

Estudos sobre família em situação de risco pessoal e social têm atraído a atenção de pesquisadores no campo das ciências humanas. De acordo com Sarti (1995), a definição de família para os pobres não se vincula a um grupo genealógico ou ao parentesco, mas está associada àqueles em que podem confiar. A noção de família define-se em torno de um eixo moral, ou seja, dispor-se as obrigações morais é o que define a pertinência do eixo familiar. O modelo de família historicamente imposto aos pobres é patriarcal e hierárquico, no entanto, no cotidiano essa realidade não se sustenta (Narvaz \& Koller, 2006). A realidade mostra, como revelam Silveira, Falcke e Wagner (2000), a existência predominante do modelo de família pobre monoparental, em sua maioria, chefiada por mulheres. Segundo Amazonas, Damasceno, Terto e Silva (2003), as famílias das camadas populares possuem algumas particularidades, embora tendam a se aproximar do modelo familiar burguês. Mesmo sofrendo a influência dos valores e modelos ideais vigentes, essas famílias pobres diferem significativamente das burguesas, pois necessitam desenvolver estratégias de desenvolvimento compatíveis com suas necessidades econômicas. Toda sua rede familiar participa da manutenção do grupo, tanto no provimento de sustento quanto no cuidado de seus membros. Os autores denominam essa organização como lógica da solidariedade, a qual garante a existência frente a um contexto que oprime seu desenvolvimento. No entanto, Amazonas et al. (2003) afirmam que essa solidariedade não significa harmonia e consenso nas famílias, pois é comum a presença de conflitos, violência, uso de drogas, divórcios e recasamentos.

A família pode ser um fator de risco ou proteção no desenvolvimento de seus componentes. Por um lado, autores apontam as interações positivas que as famílias podem utilizar e construir diante de situações de estresse e vulnerabilidade social denominando resiliência familiar (Cecconello, 2003; Hawley \& DeHaan, 1996; Walsh, 1996, Yunes, 2001). Por outro, eventos de risco podem produzir maior vulnerabilidade social das famílias (Silva, 2004). A condição socioeconômica precária das famílias impõe maiores dificuldades para a sobrevivência e pode agravar ou desencadear episódios de risco, como abandono, negligência e violência (Gomes \& Pereira, 2005). Tal escassez de recursos materiais e afetivos pode ter como conseqüência a saída para o contexto da rua da criança ou adolescente como resultado negativo e imediato dessas condições.

A vinculação com a família sempre foi mencionada como um dos principais fatores a serem considerados na descrição de jovens em situação de rua. Este, entre outros aspectos, aparece como indicador básico para caracterizar a relação que crianças e adolescentes estabelecem com a rua (P. J. Alves, 1998; Aptekar, 1996; Forster, Barros, Tannhauser, \& Tannhauser, 1992; Hutz \& Koller, 1999; Martins, 1996). Essa discussão foi nutrida por pesquisadores no final dos anos 90 do século passado, a fim de delimitar a diferença entre "crianças de rua" e "crianças na rua". O primeiro grupo (de rua), caracterizado por aqueles que não possuem mais vínculo familiar estável, é o de crianças que abandonaram ou foram abandonados pela família, e passam a maior parte do tempo nas ruas. Assim, o "viver na rua" representa seu desenvolvimento, socialização, interações, trabalho, educação e lazer. Tal definição indica que a socialização dessas crianças ocorre pela dinâmica da rua, a qual tem suas próprias leis (Bandeira, Koller, Hutz, \& Forster, 1994; Forster et al., 1992). O outro grupo, chamado de "meninos na rua", é o de crianças e adolescentes que possuem laços familiares, apesar de apresentarem uma aparência de abandono. São aqueles que utilizariam o espaço da rua como lugar de lazer e trabalho, visando a obter seu sustento e auxiliar a família, mas retorna diariamente para casa (Forster et al., 1992). Entretanto, A. J. Alves (1991) afirmou que essa distinção está superada, pois sempre foi bastante tênue, já que é difícil limitar com precisão estes vínculos e a utilização do espaço da rua. A maioria das crianças e adolescentes encontrada na rua não é abandonada, pois, geralmente, mantêm mais ou menos um ponto de referência com relação ao grupo familiar. Vários estudos que investigaram a relação destes jovens com a família, escola e atividades diárias mostraram a impossibilidade de definir os grupos separados (Bandeira et al., 1994; Koller, 
1994; Raffaeli et al., 2001). Devido à complexidade do espaço da rua e às dificuldades de definição desta população, Koller e Hutz (1996) sugeriram a denominação deste grupo como crianças em situação de rua. Tal denominação gera um impasse metodológico na homogeneização de um grupo para ser estudado, mas ressalta a necessidade de um entendimento mais aprofundado da história de vida de cada criança, a fim de agrupá-las por semelhanças, mas respeitando suas individualidades e a dinâmica intrínseca de suas realidades de vida. Definições possibilitam uma amplitude de informações sobre a relação que essas crianças e adolescentes estabelecem com o espaço da rua e com suas famílias. Recentemente, foi associada a vinculação com a família a outros fatores que podem definir a criança "em situação de rua".É apontada ainda a atividade exercida, a aparência, o local em que se encontra a criança ou o adolescente e a ausência de um adulto responsável junto à mesma, e o horário de permanência da criança na rua (Neiva-Silva \& Koller, 2002; Paludo \& Koller, 2004). Estes indicadores permitem estabelecer uma definição mais acurada do que a literatura que os caracteriza como "meninos(as) de rua" ou "meninos(as) na rua".

Os jovens que utilizam o contexto da rua como espaço de moradia e socialização possuem famílias, embora as crenças que permeiam a sociedade parecem indicar o contrário. Se as crianças moram na rua é porque não possuem família, uma vez que se tivessem, "naturalmente" estariam em casa. Teorias populares como estas traduzem denominações para essa população como "filhos de ninguém" o que, de alguma forma, justificaria a presença desses na rua. Assim, a falta de laços estáveis, sangüíneos ou não, tornar-se-ia motivo para migração ao contexto da rua. A falta de responsabilidade de um adulto que ocupa a posição de pai/mãe, e que duvida ter este compromisso de alguma forma, isenta qualquer outra pessoa de cuidar da criança. A literatura reitera e confirma a existência de vínculos familiares das crianças e adolescentes em situação de rua (Neiva-Silva, 2003; Paludo, 2004; Santos, 2004). Um importante estudo sobre o perfil das crianças "em situação de rua" na Grande Porto Alegre entrevistou 825 jovens, $79 \%$ do sexo masculino e $21 \%$ do sexo feminino, e revelou dados sobre as relações familiares estabelecidas nessa população (Furtado, Gehlen, \& Silva, 2004). Um interessante resultado sobre os vínculos familiares indicou que $94,4 \%$ dos participantes afirmaram ter mãe e $81,5 \%$ a citaram como parte da família. Em relação à figura paterna, $77,4 \%$ afirmaram ter pai, mas apenas $48,8 \%$ o consideram como parte de sua família. Outra figura citada por $42,9 \%$ foi o padrasto, uma vez que $24,2 \%$ moram com este e $10,9 \%$ o consideram como membro de sua família. Destaca-se a referência aos irmãos, 98,8\% dos participantes indicaram a existência deles e $77,4 \%$ os considera parte da família. O estudo evidenciou que apenas $8,9 \%$ da população total investigada não possuem contato com a família. Esse resultado reforça a idéia de que a maioria dos jovens que vive "em situação de rua" possui adultos responsáveis e estabelece contato, efetivo ou esporádico, com essas pessoas que consideram parte de sua família.

Abdelgalil, Gurgel, Theobald e Cuevas (2004) investigaram as características das famílias que vivem nas ruas da cidade de Aracaju, no Nordeste do país. Os autores destacaram o extensivo número de componentes na família, a chefia dessas por parte das mulheres, a história de violência, o uso de drogas e o desemprego. Identificaram, ainda, que a baixa escolaridade e a alta taxa de desemprego aparece fortemente associada com o trabalho dos filhos e com a saída desses para a rua. Por fim, ressaltam que mesmo após a saída de suas casas, os jovens "em situação de rua" mantêm contato com suas famílias. Esses dados refletem a situação enfrentada pelas famílias que vivem em situação de risco pessoal e social.

Nesse sentido, é possível verificar a existência de vínculos familiares na trajetória de crianças e adolescentes "em situação de rua". No entanto, esses vínculos devem ser analisados de forma dinâmica e contínua, devido às frequientes oscilações no grau e na configuração. Ao abordar a realidade vivida por essa população e por suas famílias é preciso refletir a família contextualizada. Essa questão merece ser compreendida em sua totalidade, não se restringindo apenas à existência de contato familiar ou, ainda, se existe realmente alguma família.

\section{Método}

\section{Participantes}

Este estudo foi desenvolvido com 17 crianças e adolescentes "em situação de rua", com idades entre $11 \mathrm{e}$ 16 anos $(M=14,05 ; D P=1,24)$, de ambos os sexos ( $29 \%$ de meninas e $71 \%$ de meninos), da cidade de Porto Alegre. Elas foram identificadas de acordo com os critérios estabelecidos para essa população (Neiva-Silva \& Koller, 2002; Paludo, 2004).

\section{Instrumentos e procedimentos}

Foi realizada uma entrevista semi-estruturada, com o objetivo de coletar dados bio-sócio-demográfios dos participantes e dados sobre a dinâmica e a configuração das famílias. Questões sobre os componentes da família, número de irmãos, trabalho dos pais, relacionamento, motivo de saída para a rua, entre outros aspectos relevantes para o entendimento do funcionamento familiar foram contempladas na entrevista. Foi feita a aplicação individual deste instrumento para que as respostas de um 
participante não influenciassem as respostas de outras crianças presentes. Devido à situação particular da rua e às próprias características dessa população, foi necessário um treinamento teórico, ético e metodológico para realizar a coleta de dados no contexto da rua e a utilização de uma abordagem específica (Paludo \& Koller, 2004). Para isto, a equipe de pesquisa se propôs a uma inserção no ambiente ecológico da rua no qual estão esses meninos e meninas, com o objetivo de conhecer a sua realidade, acompanhando-os através de visitas freqüentes à rua e às casas de acolhimento através de observações, conversas informais e entrevista propriamente ditas (Cecconello \& Koller, 2004).

\section{Resultados e discussão}

Nessa seção serão apresentados e discutidos os resultados obtidos nas entrevistas sobre a configuração e a dinâmica das famílias das crianças e adolescentes "em situação de rua". Os dados foram submetidos a uma análise qualitativa segundo o método de Bardin (1977/1979). Foram definidos cinco eixos temáticos para facilitar a discussão e a análise dos resultados, a saber: relação que a criança em situação de rua mantém ou mantinha com a família; configuração familiar; contato com a família; motivos para a saída da família e atividades laborais exercidas pelos responsáveis.

O primeiro eixo temático investigou a relação que a criança e o adolescente "em situação de rua" mantêm ou mantinha com suas famílias. Os resultados apontaram que a existência de crianças na rua não implica a inexistência da família. Todos os participantes possuíam vínculos com suas famílias, mesmo que frágeis. Dentre os participantes, apenas cinco indicaram que voltavam para suas casas todos os dias, e utilizaram como referência a composição da família atual. Já aqueles que não possuíam uma relação estável com a família indicavam a configuração familiar que possuíam antes de sair de suas casas. Essa é uma distinção apontada entre os jovens que utilizam a rua como espaço de moradia e aqueles que a utilizam como local de trabalho e lazer. É uma referência à já mencionada distinção entre meninos "de" rua e meninos "na" rua (A. J. Alves, 1991; Forster et al., 1992; Hutz \& Koller, 1999). É interessante que os próprios jovens salientam sua "definição" ao falar sobre a sua vinculação com a rua. O menino Felipe*, de 14, anos relatou que, muitas vezes, durante o tempo que fica trabalhando no centro da cidade, os traficantes o procuram para vender drogas, pois acreditam que "ele é de rua", conforme pode ser constatado em seu relato: "Eles são da rua aqui onde eu trabalho. Que eles pensam que eu também sou da rua, né. E eu falo que não." É possível identificar a resistência inicial em assumir a identidade como meninos e meninas de rua quando existem laços familiares presentes no cotidiano desses. O contrário não é indicado, ou seja, ao perceber a fragilidade dos vínculos familiares os jovens estreitam a relação com a rua.

Nesse estudo a definição de família foi dada pelos adolescentes a partir do questionamento de quem fazia parte da família deles. A configuração familiar foi o segundo eixo temático investigado. Os participantes indicaram pai, mãe, avó, amigos, padrasto ou vizinhos como integrantes da mesma. Esse resultado corrobora a diversidade de relações presentes nas famílias atuais, ou seja, compreendem-na como um sistema formado por pessoas que se relacionam por parentesco ou por se considerarem pertencentes aquele contexto (De Antoni \& Koller, 2000). A partir dos resultados pode-se compreender o verdadeiro significado dessa instituição para cada participante. Em geral, as famílias possuem um grande número de integrantes, sendo compostas principalmente por mães, irmãos e padrasto, como pode ser visto na Figura 1.

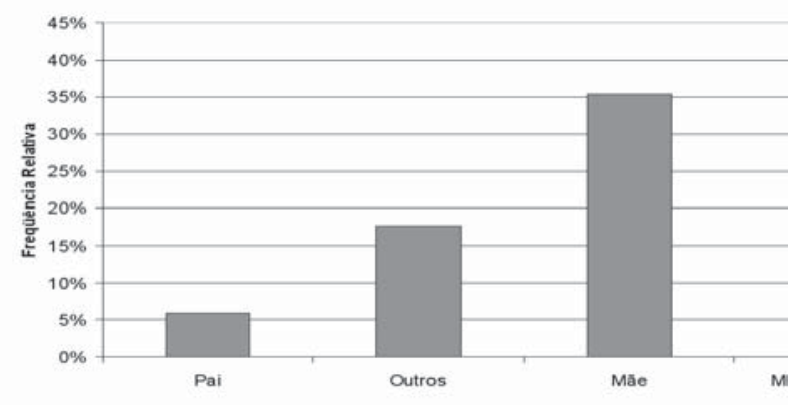

Figura 1. Configuração familiar dos participantes do estudo.

Pode-se observar que $41 \%$ dos participantes relataram morar com a mãe e padrasto e $35 \%$ afirmaram morar apenas com a mãe (ver Figura 1). Identificou-se que a mulher cuidadora tem grande importância dentro da estrutura familiar desta população. Somando-se os adolescentes que moram apenas com as mães e aqueles que vivem com a mãe e o padrasto, $76 \%$ mantêm contato dentro de casa com a figura materna. Os resultados desta pesquisa indicam que a mãe continua sendo o elemento principal dentro do lar, mas não o único. Foram citadas, ainda, outras mulheres cuidadoras, como as avós e tias. Um dado de destaque é a falta da figura paterna nessas famílias. Apenas $6 \%$ dos entrevistados indicaram o pai como parte integrante da família. Talvez a ausência do pai biológico nessas famílias possa ser explicada pelo fato de que $58 \%$ dos entrevistados afirmaram não conhecer a identidade do mesmo. Tal informação, segundo eles, é mantida sob "sigilo" pela mãe. Assim, desconhecem parte da própria história e da identidade. No entanto, esse papel é desempenhado por padrastos, tios, avôs e outras figuras masculinas presentes no cotidiano desses jovens. 
Diante deste cenário, os participantes reconhecem como família diversos arranjos. Dessa forma, quatro categorias foram identificadas e analisadas dentro do segundo eixo temático sobre a configuração familiar, a saber: famílias reconstituídas, famílias monoparentais, família nuclear e ausência de família.

A categoria famílias reconstituídas foi identificada como a mais freqüente nessa população, uma vez que $41 \%$ relataram morar com a mãe e o companheiro. Além disso, pode ser constatada a diversidade de seus arranjos a partir da análise de seus componentes, casamentos e recasamentos. No discurso de Felipe*, 14 anos:

Minha família é assim um pouco diferente. Eu tenho um monte de irmão, já nem sei mais quantos... É que assim, meu pai casou com a minha mãe e teve eu e mais dois. Depois minha mãe teve outros filhos com meu padrasto. Meu pai, daí, casou com a minha tia, irmã da minha mãe, então, eu tenho irmãos que são primos, não é isso! Tá agora, meu pai casou com a minha avó, mãe da minha mãe. Agora já me perdi não sei mais o que meu pai é... Só sei que minha família é grande. Somos um monte lá em casa, tem uns que moram nos fundos e tem meus cachorros também... Já são da família. Acho que família é isso. Tenho uns irmãos de rua, sabe. Não são meus irmão de verdade, de sangue, mas considero da minha família. Tem um que tá morando lá em casa...

A profusa configuração foi descrita naturalmente pelos jovens ao falar a respeito das diferentes formas como que a família se apresenta. Essas situações foram abordadas e interpretadas como cotidianas e "normais". A familiaridade com o recasamento e separações é tão presente na vida dessas crianças e adolescentes que, quando questionados sobre suas famílias, encontram dificuldades de nomear o número de irmãos, padrastos e parentes que possuem. Embora acompanhem todo esse processo, de forma direta ou indireta, assistindo e conhecendo os novos companheiros da mãe, apresentam dificuldade na compreensão da filiação diante de novas configurações nas suas famílias.

A categoria família monoparental foi apontada por $35 \%$ dos participantes. Essa está relacionada à presença de apenas um chefe de família, papel exercido geralmente pela mulher. O relato de Joana*, 14 anos pode exemplificar essa realidade:

Na minha casa morava eu, minha mãe e minha irmã. Meu pai não sei quem é, nunca vi, minha mãe também nunca me contou nada sobre ele. Ela dizia que bastava pra nós... Até funcionava bem, mas daí eu conheci um cara, me apaixonei, sabe... Então, eu fui morar com ele... Minha mãe deixou, até gostava dele, mas não deu certo... Fugi, agora to aqui... Minha mãe ta morando em outro estado, vou tentar conseguir dinheiro pra ir pra casa...

Segundo Silveira et al. (2000), o modelo monoparental é dominante nas famílias das camadas po- pulares. A mulher assume o papel de chefe de família. Dessa forma, podem ser discutidas a centralização e as novas funções que essa adquire especialmente a organização e a manutenção da casa.

Entretanto, a monoparentalidade não significa que os filhos não estejam expostos a outras figuras de autoridade na família. É preciso considerar as constantes e sucessivas uniões dessas mulheres, denominado por Bilac (1995) como "monogamia seriada". A busca de novos parceiros pode ser indício de uma preocupação econômica, uma vez que esses podem tornar-se novos provedores da casa. No entanto, a solução para um determinado problema pode disseminar outros, como comportamento agressivo e situações de violência. $\mathrm{O}$ relato da menina Vivian*, 13 anos, traduz essa situação:

Minha mãe já teve vários namorados, a gente tinha que dizer que eram padrastos! Padrastos!?Às vezes, só passavam uma semana lá em casa, o último que ficou lá era nojento. Ela [mãe] que me mandou sair de casa por causa dele [padrasto], eu não queria sair de casa. Ele [padrasto], aquele nojento, ele abusava de mim, ela sabia, claro que sabia... todo mundo sabia... Mas ela disse que era por causa que eu dava muita confusão para ela por causa do conselho tutelar. Me mandou embora de casa, disse que não queria ver mais em casa, nem me ver mais lá. Não sei me deu uma coisa assim, eu não conseguia mais falar. Não sei, comecei a chorar. Eu não queria ficar longe dos meus irmãos, não queira ficar longe da minha mãe. Do meu padrasto eu queria ficar longe porque ele me maltrata muito. Ele me batia com tudo o que tem pela frente... Me sinto assim, estranha porque eu queria estar em casa, sabe... É tinha vezes que tinham que me segurar porque eu me cortava com caco de vidro, me machucava aqui olha!. Eu penso porque que eu não morri, só nisso que eu penso. Eu fico pensando, queria ser como as outras pessoas, assim não ter passado por nada disso, não estar na rua, estar em casa, ter onde dormir, ter onde ficar.

Embora a diversidade das configurações familiares seja apontada como dominante nessa população, foi encontrado um relato sobre família nuclear. O menino de 14 anos afirma:

Minha família é grande, sou eu, minha mãe, meu pai e meus 12 irmãos. Tens uns que já moram em outras casas, mas são minha família. É tudo que eu tenho, minha família. Eu tenho família, sabe, pensam que eu sou de rua porque trabalho aqui, mas eu não sou, tenho família e moro na minha casa. Eu trabalho desde os 8 anos, sabe, vendia suco no sinal... Mas aí, sabe como é, criança não pode trabalhar, tive que sair. Mas como assim, lá em casa tem um monte de gente, tenho 12 irmãos... Minha mãe não trabalha, ai já viu, se a gente não levar dinheiro como vamos comer, e tem que comprar a fralda da menor... Eu quero ter família um dia, mas só quero ter um ou dois 
filhos... Dá muita trabalho, né. E sai caro também. Assim, sobra mais espaço na casa...

Esse depoimento traduz o funcionamento das famílias que vivem em situação de pobreza. Primeiro, ressalta o número extensivo de irmãos, o qual variou na amostra $(\mathrm{N}=17)$ entre um e $12(\mathrm{M}=5,69, \mathrm{DP}=3,07)$. Segundo, devido à necessidade real de manutenção da família, tanto econômica quanto emocional, são desenvolvidas estratégias de sobrevivência, como a procura por trabalho no espaço da rua. A busca de sustento financeiro e a exploração do trabalho infantil doméstico tornamse realidades diárias e uma porta de entrada para a condição de criança em situação de rua (Santana, 2003).

Além dessas configurações familiares, foi encontrada uma menina que não conheceu nenhum membro de sua família:

Eu não conheço ninguém da minha família... Minha mãe me abandonou aos 6 meses de idade, só sei que o nome dela é F. Eu morei a vida toda em instituições e tenho várias tias que cuidaram de mim. Não sei se tenho irmão e irmã. Mas eu sei que a minha mãe fez o melhor pra mim... Eu não sei por que ela [mãe] me deixou, entende, eu não vou julgar ela pelo negócio que eu não sei. Talvez ela teve que fazer isso pra alguma coisa, algum negócio. Tenho certeza de que ela achou que estava fazendo o melhor pra mim... Posso não saber nada, mas tenho certeza de que a minha mãe me ama... Ah, eu sei lá... ah não sei como seria se reencontrasse minha mãe. Não sei se poderia ser diferente ou não. Eu sei lá, eu levo tudo para o outro lado, assim sabe..Eu quero ter minha família, um marido, meus filhos...

A ausência total da família é, muitas vezes, encontrada na trajetória de vida das crianças e adolescentes institucionalizados e/ou em situação de rua. No abandono total, não só o caráter definitivo do abandono é vivenciado, como também, todas as perdas secundárias. Ou seja, perde contato com todas as figuras afetivas de referência, a família extensa, o espaço físico familiar, a rotina e, até mesmo, os hábitos da família de origem. No entanto, é interessante ressaltar a expectativa futura em relação à construção da própria família. Pode ser identificado nesse relato, como de outros participantes, a expectativa de uma melhoria na qualidade de vida, que rompe com o modelo vivenciado pelos mesmos. Em suas crenças, o modelo nuclear aparece como ideal e como resolução dos problemas enfrentados no cotidiano. Podese, ainda, inferir o desejo de se aproximar do modelo tradicional e predominante na sociedade burguesa a fim de minimizar o sentimento de exclusão social. Essa idealização das relações familiares corrobora os estudos realizados sobre a temática no contexto de famílias de nível socioeconômico baixo (Cecconello, 2003; De Antoni \& Koller, 2000; Szymanski, 1997).
O terceiro eixo temático investigado foi o contato estabelecido entre os participantes e os membros de suas famílias. Através dos dados obtidos, apenas uma menina $(6 \%)$ não conhece nenhum familiar e afirma não ter família, pois foi abandonada aos seis meses de idade. Somente $29 \%$ dos participantes relataram ir para casa todos os dias, ou seja, pertencem ao grupo de meninos que utiliza a rua como espaço de sobrevivência e sustento familiar. O restante dos participantes afirmou manter algum tipo de contato esporádico, $29 \%$ afirmaram ter visitado suas casas há um mês, $12 \%$ há três meses, $18 \%$ há um ano e $6 \%$ há dois anos. É notável confirmar que $94 \%$ dos participantes indicam a presença de familiares em seus discursos e em seu cotidiano.

As crianças e adolescentes "em situação de rua" possuem famílias, contrariando as corriqueiras "crenças" populares. A concepção de família é dada principalmente pelos laços afetivos. Diferentes configurações familiares foram encontradas e não existe um modelo padrão. Esse resultado corrobora o estudo de Furtado et al. (2004) ao indicar a presença dos vínculos familiares, efetivos ou esporádicos, na vida dos jovens em situação de rua.

Peculiaridades provenientes das dificuldades econômicas e afetivas vivenciadas por essas famílias, as quais implicam na saída precoce desses meninos e meninas dos lares para o contexto da rua, serão destacadas no quarto eixo temático. Gomes e Pereira (2005) indicam que as principais consequiências da situação econômica precária das famílias repercutem diretamente sob os mais vulneráveis desse grupo: os filhos. Para eles, vítimas da injustiça social e violados em seus direitos fundamentais, a vida na rua pode representar uma alternativa para romper com o ciclo e o processo de vitimização que sofrem, seja na família de origem, seja na própria sociedade. Vários estudos investigaram os principais motivos que provocaram a saída destes de suas casas (Aptekar, 1989; Bandeira et al., 1994; Koller \& Hutz, 1996). De maneira geral, os problemas sociais, econômicos e afetivos são apontados como principais fatores que influenciam a saída para a rua. A Figura 2 apresenta os principais motivos de saída para rua apontados pelos participantes do estudo $(N=17)$.

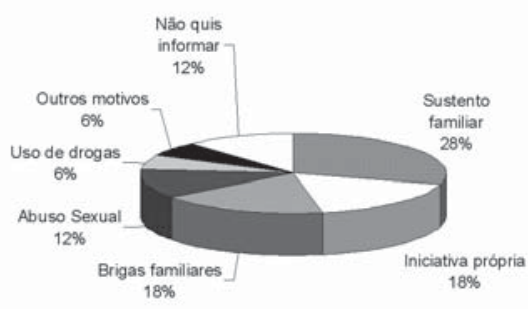

Figura 2. Motivos de saída para a rua das crianças e adolescentes em situação de rua participantes. 
Quando questionados sobre os motivos que os levaram à saída de suas casas, $12 \%$ dos entrevistados não quiseram informar o evento ou a justificativa para sua migração. $\mathrm{O}$ fato de negarem a resposta a essa questão, levanta a hipótese sobre a dificuldade de falar sobre assuntos relacionados, diretamente, aos vínculos afetivos e ao contexto familiar. Apenas $29 \%$ dos adolescentes mencionaram a necessidade de ajudar no sustento familiar como seu principal motivo. É interessante salientar que essas respostas foram dadas pelas crianças que possuem vínculo efetivo com suas famílias $(\mathrm{n}=5)$. Nesse caso, o espaço da rua é utilizado apenas para o trabalho:

$\mathrm{Eu}$ estudo de manhã, e na quinta e sexta eu solto cedo, às 10 hs. Daí eu venho para cá trabalhar. Aqui comecei com 12. Antes eu trabalhava assim de vender suco... Na sinaleira, suco de garrafinha. Tive que parar, porque fizeram uma, disseram que não dava para trabalhar, parece que tava dizendo que menor não pode trabalhar, que tá explorando, daí eu fui para casa. Agora gosto mais de trabalhar de engraxar. Aqui e lá no Parcão, na Goethe, na Cidade Baixa... Mas o lugar que eu mais gosto é aqui... Depois umas sete horas eu vou pra casa....

Todos foram entrevistados durante o período de trabalho, especialmente no centro da cidade, onde procuravam clientes para obter o dinheiro do dia.

Eu ajudo também em casa. Só que daí se eu fico em casa não tem o que comer à noite. Daí fica ruim. Ontem eu fiz quinze, né! Levei dez pra casa, e cinco eu comprei a fralda pro meu irmão. Um pacote de fralda. E daí deu só pra janta. Daí hoje de meio dia meu pai teve que vender a latinha que ele tinha pra poder comer de meio dia. (Felipe*, 14 anos, engraxate).

Ainda em relação aos motivos apontados, destacam-se as categorias brigas familiares e iniciativa própria. Ambas representam 18\% das respostas da amostra e envolvem, de maneira direta ou indireta, a violência doméstica. Estudos confirmam esse tipo de violência como um importante motivo para que as crianças abandonem suas casas (Aneci Rosa, Borba \& Ebrahim, 1992; Aptekar, 1996). A maioria dos casos de maus tratos ocorre dentro das próprias residências, tendo como principal agressor alguém com um grau parentesco com o abusado, seja esse pai, mãe, padrasto, madrasta, tio, entre outros. Segundo Koller e De Antoni (2004), definem essa violência como ações e/ou omissões que podem cessar, impedir, deter ou retardar o desenvolvimento pleno dos seres humanos. Esses atos são cometidos por adultos que deveriam ser, a princípio, responsáveis pela segurança, proteção e supervisão da criança ou do adolescente.

Os relatos sobre os motivos de saída vinculados à categoria denominada "iniciativa própria" referem-se, principalmente, às fugas motivadas pelos maus tratos dos familiares:
Morei, de 1 ano até os 3 . Ai dos 3 até os 7 morei com o meu pai... Por causa que não deu certo com um nem com o outro, daí eu fugi de casa. Ah, meu pai bebia, batia daí eu peguei e fugi de casa, eu quis, não dava mais... (Eduardo*, 15 anos).

Outro fator apontado pelos meninos, ainda referente à fuga, deve-se a furtos na comunidade onde moravam "... Por causa que na boca do meu pai to sujo [risos]. Ah, aprontei várias coisas... roubei bicicleta, vídeo cassete, televisão... da vizinhança. Tive que fugir, não posso voltar mais lá!" (Junior*, 13 anos), ou furtos dentro da própria casa, conforme o relato de Tiago*, 14 anos: "Não posso ir pra casa. Por causa do meu padrasto. Ah, porque eu roubei o cavalo dele, e agora ele quer me pegar. Eu não volto mais lá, não gosto. Eu quis sair de lá”. As justificativas e motivações das brigas familiares são as mais diversas, no entanto, provocam a saída dos jovens de suas casas

Briguei com a minha família, é a segunda vez já que eu tô na rua. Já tinha vindo pra rua antes, fiquei 3 meses já na rua. Foi em fevereiro. Eu tinha brigado também com a minha mãe... tudo por causa do meu irmão. Ele fica mexendo comigo, fica implicando, bate no cara só por causa de que ele é maior. Ai eu brigava com ele e a minha mãe batia em mim. (Raul*, 14 anos).

Um único episódio de briga foi motivo suficiente para a saída de casa de uma jovem que já havia constituído sua própria família:

Fazia 8 meses, fazia 8 meses que a gente tava junto. Eu briguei porque ele me traiu com uma colega de serviço dele, ficou com ela, mas ai ele falou que ficou só um dia e não sabia que eu tava desconfiada que tava grávida. Mas assim mesmo eu não perdoei, não acreditei.

Outro fator que merece consideração é a saída de casa devido a situações de abuso sexual, conforme apontado na entrevista. A violência sexual corresponde aos atos de natureza sexual impostos a uma criança ou adolescente por um adulto que explora seu "poder", sob a forma de assédio verbal, invasão de limites corporais ou psicológicos através de toques ou palavras, e relações sexuais genitais, orais ou anais (De Antoni \& Koller, 2002). Esse tipo de violência pode ser encontrado nos relatos das meninas:

Eu saí de casa, por causa que quase fui estuprada pelo meu padrasto. Esses dias eu tava na cama ai ele pegou e passou a mão em mim, minha mãe foi trabalhar... Começou a passar a mão em mim... a mão em mim... e só. Aí eu comecei a gritar, aí eu fui pra sala e fiquei assim como eu tô [ela nos mostra a posição em que ficou, encolhida com as pernas e os braços encolhidos junto ao corpo]. Ele falava que se eu contasse para a minha mãe ele ia mandar as gurias me 
bater. Eu apanhava um monte, de várias gurias eu apanhava... daí eu saí de casa... (Camila, 15 anos).

O uso de drogas (6\%) também foi indicado como um dos facilitadores para o abandono dos lares.

A partir desses relatos percebe-se a necessidade de priorizar as questões que antecedem à saída para a rua, muitas dessas poderiam ser esclarecidas ou amenizadas a partir de programas preventivos, que promovam redes de apoio sociais e efetivas com essas famílias. De maneira geral, o fator que é bastante relevante e que permeia a saída desses adolescentes para a rua, independente da motivação indicada, ainda é a atual situação econômica do país. Muitas famílias sobrevivem abaixo da linha da miséria. Afalta de educação formal dos pais impossibilita a aquisição de um emprego e, consequentemente, de condições financeiras para manter a família. A falta de emprego dos pais, o número extensivo de integrantes na família, as dívidas, o local de moradia que, muitas vezes, é afastado dos centros comerciais e implicam gastos com transporte, entre outros fatores, contribuem para essa migração, e tornam essas pessoas ainda mais vulneráveis. Dessa forma, esses fatores incrementam, de forma significativa, a saída das crianças e adolescentes para a rua, a fim de obter ganhos financeiros para colaborar com o sustento familiar.

A falta de oportunidade da família permeia o cotidiano dos jovens em situação de rua. Essa realidade encontrada no sul do país assemelha-se a realidade vivenciada por famílias "em situação de rua" no Nordeste apresentada no estudo de Abdelgalil et al. (2004). Esses dados remetem à reflexão da família como um todo. Uma interessante discussão apontada por Kaloustian e Ferrari (1994) refere que a criança excluída da escola, presente nas favelas e no trabalho infantil está intimamente vinculada à família que está abandonada e desassistida pelas políticas públicas e pela sociedade.

O quinto eixo temático analisado caracterizou as atividades laborais exercidas pelos responsáveis. A Figura 3 apresenta as atividades exercidas pela mãe e a Figura 4 as atividades exercida pelo pai dos participantes desse estudo.

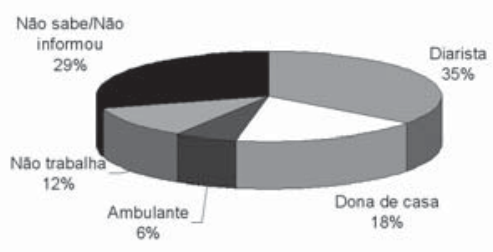

Figura 3. Trabalho realizado pelas mães dos participantes do estudo.

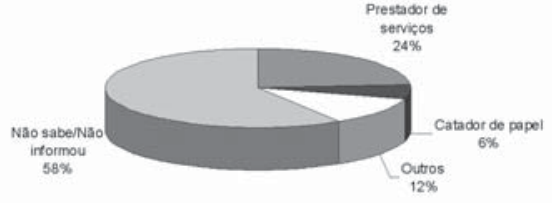

Figura 4. Trabalho realizado pelos pais dos participantes do estudo.

Apenas $42 \%$ dos pais e $41 \%$ das mães exercem alguma atividade laboral. $\mathrm{O}$ trabalho exercido pelos pais caracteriza-se pelo trabalho informal, o qual não oferece estabilidade financeira ou garantia de recurso financeiro diário. Isso implica a necessidade do envolvimento de outros membros da família em atividades de trabalho para o sustento da mesma. Muitas vezes, a criança torna-se um importante auxiliar financeiro.

Essa realidade é encontrada nas diferentes configurações familiares. Entretanto, o trabalho infantil parece oferecer diferentes significados para as famílias monoparentais. A ausência de outro adulto responsável implica na participação direta da criança ou do jovem nas atividades que possibilitam o sustento da casa. Nesse estudo, destaca-se a ausência da figura paterna nessas famílias, a qual desperta reflexão. O desconhecimento, o abandono ou, até mesmo, a negação do pai frente ao papel que "deveria" exercer tornam essas famílias mais vulneráveis, tanto financeiramente quanto emocionalmente. Essa afirmação pretende destacar que o pai é mais uma pessoa adulta que poderia auxiliar no cuidado e no aporte financeiro para essas famílias. Certamente, a fragilização financeira dessas famílias, devido à falta da contribuição de mais um adulto responsável influencia, diretamente, no desenvolvimento emocional, social, cognitivo e físico dessas crianças. As dificuldades do mercado de trabalho para a mulher agravam isto e ficam evidentes na ausência de atividade laboral da mãe, uma vez que 59\% dessas mulheres não possuem qualquer tipo de atividade que produza ganho financeiro. Dessa forma, as mães solicitam que os filhos assumam o sustento da família, indo para as ruas trabalhar como engraxate, esmolar, cuidar de carros, entre outras atividades que possam ajudar economicamente em suas casas. Essas atividades são exercidas em diferentes locais e momentos e fazem parte do cotidiano desses jovens (Santana, Doninelli, Frosi \& Koller, 2005; Yunes, Arrieche \& Tavares, 1997). Esse novo papel assumido por esses meninos e meninas promove um distanciamento da infância e das atividades típicas desse período.

As famílias dessa população precisam desenvolver estratégias de sobrevivência, sejam essas econômicas e/ ou afetivas. Toda a rede familiar necessita participar para 
a "manutenção" do lar e, muitas vezes, a saída para o contexto da rua é a alternativa para alcançar esse objetivo. Embora essa afirmação pareça contraditória é bastante vivenciada pelos meninos e meninas que estão nas ruas. Por outro lado, a exposição dessas crianças ao "ambiente da rua", à instabilidade dos vínculos familiares, à miséria, bem como o afastamento da escola, das brincadeiras e dos amigos que seriam esperados para a sua faixa etária, tornam-se fatores de risco poderosos ao desenvolvimento saudável. E, consequentemente, impulsionam à saída dessas crianças de suas famílias.

Carpena (1999) investigou essa problemática da migração para a rua, a partir da perspectiva que as famílias possuem sobre essas crianças e adolescentes que saem de casa. Seu estudo revelou a percepção que as famílias de meninos e meninas "em situação de rua" possuem sobre a situação atual de vida destas crianças, sua saída de casa e as expectativas sobre o futuro. Os resultados indicaram a presença de dificuldades no relacionamento familiar antes da migração e durante o período que as crianças estão na rua. Os sentimentos de preocupação, culpa e impotência foram os fatores mais apontados pelos responsáveis, quando questionados sobre a saída do filho de suas casas. Esse dado é ressaltado à medida que estes afirmam serem conscientes dos riscos existentes no ambiente da rua e das atividades prejudiciais nas quais seus filhos estão envolvidos. No entanto, não existe uma mobilização efetiva aparente por parte da família que indique a busca de reversão desta situação.

Essas crianças estão em idade escolar e não possuem maturidade cognitiva, emocional e física para sobreviverem sozinhas em um ambiente caracterizado por diversas situações de risco. Em vista disso, é importante e fundamental que a sociedade, as instituições e a escola ofereçam atenção imediata a esse problema social, a fim de resgatar os vínculos afetivos e o comprometimento com a vida. Novamente, esses dados evidenciam a importância da criação de medidas preventivas, abordando desde as famílias de origem até a sociedade em geral. As crianças não deveriam sair de suas casas para a rua, mas ao ocorrer esse evento, quando recém-chegadas às ruas deveriam receber uma atenção imediata, uma vez que os vínculos com a família podem ser reconstituídos mais facilmente nesse momento. As instituições e os programas sociais assumem um papel extremamente importante na vida dessa população, à medida que buscam ou recorrem a esses novos contextos para o seu desenvolvimento.

Urge transformar o olhar sobre a relação familiar que essa população estabelece em tais condições de risco pessoal e social. A rua é uma conseqüência da má resolução dos conflitos emergentes nesse ambiente. Mas, no caso dessas famílias, a existência de adversidades não significa, necessariamente, sua desconfiguração como tal. O cotidiano é permeado de situações problemáticas como, a diversidade de arranjos e configurações, as difíceis experiências e a violência vivenciadas dentro do lar e as dificuldades econômicas enfrentadas. No entanto, esses fatos per si não podem desqualificar o papel importante que as famílias assumem na vida das crianças e dos adolescentes, mas atribuir a elas também a condição de vítimas de um sistema social. Dessa forma, é imprescindível que seja oferecido um atendimento e apoio social e afetivo, uma vez que o bem-estar das famílias implica e reflete uma dimensão pública e social. É preciso fortalecêlas através da orientação de novas estratégias e recursos individuais para a superação das adversidades. Ao proporcionar tais possibilidades, a sociedade estará fortalecendo a família como um sistema social capaz de romper com a migração das crianças e jovens para o contexto da rua e, consequentemente, promovendo o processo de resiliência familiar.

\section{Referências}

Abdelgalil, S., Gurgel, R., Theobald, S., \& Cuevas, L. (2004). Household and family characteristics of street children in Aracaju, Brazil. Archives Disabilities of Children, 89, 817-820.

Alves, A. J. (1991). Meninos de rua e meninas de rua: Estrutura e dinâmica familiar. In A. Fausto \& R. Cervini (Eds.), O trabalho e a rua: Crianças e adolescentes no Brasil urbano dos anos 80 (pp. 117-132). São Paulo, SP: Cortez.

Alves, P. B. (1998). O brinquedo e as atividades cotidianas de crianças em situação de rua. Dissertação de Mestrado nãopublicada, Universidade Federal do Rio Grande do Sul, Porto Alegre, RS. Retirado de http://www.psicologia.ufrgs.br/ceprua

Amazonas, M., Damasceno, P., Terto, L., \& Silva, R. (2003). Arranjos familiares de crianças das camadas populares. Psicologia em Estudo, 8, 11-20.

Aneci Rosa, C. S., Borba, R. E. S. R., \& Ebrahim, G. J. (1992). The street children of Recife: A study of their background. Journal of Tropical Pediatries, 38, 34-40.

Aptekar, L. (1989). Characteristics of street children of Colombia. Child Abuse and Neglect, 133, 427-437.

Aptekar, L. (1996). Crianças de rua nos países em desenvolvimento: Uma revisão de suas condições. Psicologia Reflexão e Crítica, 9, 153-184.

Bandeira, D., Koller, S. H., Hutz, C., \& Forster, L. (1994). O cotidiano dos meninos de rua de Porto Alegre. In Anais do XVII Internacional School Psychology Congress: Vol. 2 (pp. 133134). Campinas, SP.

Bardin, L. (1979). Análise de conteúdo (L. A. Reto \& A. Pinheiro, Trad.). São Paulo, SP: Edições 70. (Original publicado em 1977)

Bilac, E. (1995). Sobre as transformações nas estruturas familiares no Brasil: Notas muito preliminares. In I. Ribeiro \& A. C. Ribeiro (Eds.), Famílias em processos contemporâneos: Inovações culturais na sociedade brasileira (pp. 43-61). São Paulo, SP: Edições Loyolas.

Carpena, M. (1999). Famílias de meninos e meninas em situação de rua na cidade de Caxias do Sul: Locus de controle, situação atual de vida e expectativas para o futuro. Dissertação de Mestrado não-publicada, Universidade Federal do Rio Grande do Sul, Porto Alegre, RS. 
Carter, B., \& McGoldrick, M. (1995). As mudanças no ciclo de vida familiar: Uma estrutura para a terapia familiar (M. A. V. Veronese, Trad.). In B. Carter \& M. McGoldrick (Eds.), Mudanças no ciclo de vida familiar: Uma estrutura para a terapia familiar (pp. 7-29). Porto Alegre, RS: Artes Médicas. (Original publicado em 1985)

Cecconello, A. (2003). Resiliência e vulnerabilidade em famílias em situação de risco. Tese de Doutorado não-publicada, Universidade Federal do Rio Grande do Sul, Porto Alegre, RS.

Cecconello, A., \& Koller, S. H. (2004). Inserção ecológica na comunidade: Uma proposta metodológica para o estudo de famílias em situação de risco. In S. H. Koller (Ed.), Ecologia do desenvolvimento humano: Pesquisa e intervenção no Brasil (pp. 267-293). Porto Alegre, RS: Casa do Psicólogo.

De Antoni, C., \& Koller, S. H. (2000). A visão de família entre as adolescentes que sofreram violência intrafamiliar. Estudos de Psicologia, 5, 347-381.

De Antoni, C., \& Koller, S. H. (2002). Violência doméstica e comunitária. In M. L. J. Contini, S. H. Koller \& M. N. S. Barros (Eds.), Adolescência e Psicologia: Concepções, práticas e reflexões críticas (pp. 85-91). Brasília, DF: Conselho Federal de Psicologia.

Forster, L. M. K., Barros, H. M. T., Tannhauser, S. L., \& Tannhauser, M. (1992). Meninos na rua: Relação entre abuso de drogas e atividades ilícitas. Revista da ABP-APAL, 14, 115120.

Furtado, A., Gehlen, I., \& Silva, M. (2004). A realidade das crianças e adolescentes em situação de risco social na Grande Porto Alegre: Perfis e índices de vulnerabilidade. Porto Alegre, RS: CMDCA.

Gomes, M., \& Pereira, M. (2005). Famílias em situação de vulnerabilidade social: Uma questão de políticas públicas. Ciência \& Saúde Coletiva, 2, 357-363.

Hawley, D., \& DeHaan, L. (1996). Toward a definition of family resilience: Integrating life span and family perspectives. Family Process, 35, 283-298.

Hutz, C. S., \& Koller, S. H. (1999). Methodological and ethical issues in research with street children. In M. Raffaelli, \& R.W. Larson (Eds.), Homeless and working youth around the world: Exploring deelopmental issues. New Directions for Child and Adolescent Development (Vol. 85, pp. 59-70). São Francisco, CA: Jossey-Bass.

Kaloustian, S., \& Ferrari, M. (1994). Introdução. In S. Kaloustian (Ed.), Família brasileira: A base de tudo (pp. 11-15). São Paulo, SP: Cortez.

Koller, S. H. (1994). Julgamento moral pró-social de meninos e meninas de rua. Tese de Doutorado não-publicada, Pontifícia Universidade Católica do Rio Grande do Sul, Porto Alegre, RS.

Koller, S. H., \& De Antoni, C. (2004). Violência Intrafamiliar: Uma visão ecológica. In S. H. Koller (Org.), Ecologia do desenvolvimento humano: Pesquisa e intervenção no Brasil (pp. 293310). Porto Alegre, RS: Casa do Psicólogo.

Koller, S. H., \& Hutz, C. S. (1996). Meninos e meninas em situação de rua: Dinâmica, diversidade e definição. Coletâneas da ANPEPP: Aplicações da Psicologia na Melhoria da Qualidade de Vida, 1, 11-34.

Martins, R. A. (1996). Censo de crianças e adolescentes em situação de rua em São José do Rio Preto. Psicologia Reflexão e Crítica, 9, 101-122.

Minuchin, S. (1982). Famílias: Funcionamento e tratamento. Porto Alegre, RS: Artes Médicas.

Narvaz, M., \& Koller, S. (2006). Famílias e patriarcado: Da pres- crição normativa à subversão criativa. Psicologia \& Sociedade, 18, 49-55.

Neiva-Silva, L. (2003). Expectativas futuras de adolescentes em situação de rua: Um estudo autofotográfico. Dissertação de Mestrado não-publicada, Universidade Federal do Rio Grande do Sul, Porto Alegre, RS.

Neiva-Silva, L., \& Koller, S. H. (2002). A rua como contexto de desenvolvimento. In E. R. Lordelo, A. M. A. Carvalho \& S. H. Koller (Eds.), Infância brasileira e contextos de desenvolvimento (pp. 202-230). São Paulo, SP: Casa do Psicólogo.

Paludo, S. (2004). Expressão das emoções morais de crianças em situação de rua. Dissertação de Mestrado não-publicada, Universidade Federal do Rio Grande do Sul, Porto Alegre, RS.

Paludo, S., \& Koller, S. (2004). Inserção ecológica no contexto da rua. In S. H. Koller (Ed.), Ecologia do desenvolvimento humano: Pesquisa e intervenção no Brasil (pp. 219-244). Porto Alegre, RS: Casa do Psicólogo.

Raffaeli, M., Koller, S. H., Reppold, C. T., Kuschick, M. B., Krum, F. M. B., \& Bandeira, D. R. (2001). How do brazilian street youth experience 'the street'? Analysis of a sentence completion task. Childhood, 8, 396-415.

Santana, J. (2003). Instituições de atendimento a crianças em situação de rua: A relação entre os objetivos e significados atribuídos por seus dirigentes e pelas crianças atendidas. Dissertação de Mestrado não-publicada, Universidade Federal do Rio Grande do Sul, Porto Alegre, RS.

Santana, J., Doninelli, T., Frosi, R., \& Koller, S. (2005). Os adolescentes em situacao de rua e as instituições de atendimento: Utilizações e reconhecimento de objetivos. Psicologia: Reflexão e Crítica, 18, 134-142.

Santos, E. (2004). Um estudo sobre a brincadeira de crianças em situação de rua. Dissertação de Mestrado não-publicada, Universidade Federal do Rio Grande do Sul, Porto Alegre, RS.

Sarti, C. A. (1995) O valor da família para os pobres. In I. Ribeiro \& A. C. Ribeiro (Eds.), Famílias em processos contemporâneos: Inovações culturais na sociedade brasileira (pp.131-150) São Paulo, SP: Loyola.

Silva, E. (2004). O perfil da criança e do adolescente nos abrigos pesquisados. In E. R. Silva (Ed.), O direito à convivência familiar e comunitária: Os abrigos para crianças e adolescentes no Brasil (pp. 41-70). Brasília, DF: IPEA.

Silveira, S., Falcke, D., \& Wagner, A. (2000). A representação gráfica de meninos institucionalizados. In Anais do II Congresso da Sociedade Brasileira de Rorschach e outros métodos projetivos (pp. 232-240). Porto Alegre, RS.

Szymanski, H. (1997). Teorias e "teorias" de famílias. In M. C. B. Carvalho (Ed.), A família contemporânea em debate (pp. 2327). São Paulo, SP: EDUC.

Walsh, F. (1996). The concept of family resilience: Crisis and challenge. Family Process, 35, 261-281.

Yunes, M. A. M. (2001). A questão triplamente controvertida da resiliência em famílias de baixa renda. Tese de Doutorado nãopublicada, Pontifícia Universidade Católica de São Paulo. São Paulo, SP.

Yunes, M. A. M., Arrieche, M. R. O., \& Tavares, M. F. A. (1997). Meninos(as) em situação de rua na cidade de Rio Grande: Vida na rua e vida na instituição. Momento, 10, 131-142. 
Simone dos Santos Paludo é Psicóloga pela Universidade Católica de Pelotas, Mestre e Doutoranda em Psicologia do Desenvolvimento pela Universidade

Federal do Rio Grande do Sul (UFRGS). Professor Assistente da Fundação Universidade Federal do Rio

Grande. Endereço para correspondência: Fundação Universidade Federal do Rio Grande, Departamento de Educação e Ciências do Comportamento, Av. Itália, KM 8, Rio Grande, RS, 96 201-900. Tel.: (53) 33326896 simonepaludo@yahoo.com.br

Silvia Helena Koller é Mestre em Psicologia do Desenvolvimento pela UFRGS, Doutora em Educação pela Pontifícia Universidade Católica do Rio Grande do Sul (PUC-RS), e Professora da UFRGS. Endereço para correspondência: Universidade Federal do Rio Grande do Sul, Instituto de Psicologia, Ramiro Barcelos, 2600, sala 104, Santana, Porto Alegre, RS, 90 035-003. Caixa-

Postal: 9001. Tel.: (51) 33085150 Fax: (51) 32411328 silvia.koller@pesquisador.cnpq.br

\section{Toda Criança tem Família:}

Criança em Situação de Rua Também

Simone dos Santos Paludo e Silvia Helena Koller

Recebido: 13/04/2007

$1^{\mathrm{a}}$ revisão: 05/08/2007

$2^{\mathrm{a}}$ revisão: $23 / 10 / 2007$

Aceite final: 21/11/2007 